\title{
A new treatment for congenital nystagmus
}

\author{
R. V. ABADI, D. CARDEN, AND J. SIMPSON \\ From the University of Manchester Institute of Science and Technology, Visual Sciences Laboratory. \\ Department of Ophthalmic Optics, PO Box 88, Manchester M60 1QD
}

SUMMARY Congenital nystagmus is a disorder of eye movement with an associated reduction in visual acuity. The latter is mainly due to the intensity of the nystagmus (amplitude times frequency) allowing the object of regard to spend only a short time on the fovea. Training patients by an auditory feedback technique to control the nystagmus enables visual sensitivity to improve. This method is compared with present alternatives, and further studies are suggested.

Estimations of the incidence of congenital nystagmus $(\mathrm{CN})$ in the general population vary enormously. The data of Hemmes (1926), 1 in 5000, Anderson (1953), 1 in 350, and Norn (1964), 1 in 20000 , provide a surprisingly large range, which most probably reflects not only the researchers' differing definitions of the condition but also the manner in which they collected the data. Perhaps a more clinically pertinent survey was that made by Fine (1968). She found that in England and Wales nystagmus was the fourth largest $(11 \cdot 2-14 \%)$ cause of partial sight.

In this study $\mathrm{CN}$ is defined as involuntary ocular oscillations occurring at birth or soon after (3 months), owing its origin to genetic, intrauterine, or birth influences. Characteristically, the dominant eye movements are bilateral and horizontal, although on occasion a vertical nystagmus, which usually signifies an acquired disorder, has been reported as being inherited (Forsythe, 1955; Marmor, 1973). The intensity (amplitude $\times$ frequency) of the nystagmus may vary enormously from individual to individual, and it may alter for each direction of gaze (Dell'Osso, 1973; Abadi and Sandikcioglu, 1974). Visual sensitivity for both pattern and movement detection is reduced because of these eye movements (Abadi, 1974a; Abadi and Sandikcioglu, 1975). This is understandable, since the object of regard spends little time in the foveal area, and the blur caused by the image movement, often in excess of $50 \%$, is considerable (Abadi and Sandikcioglu, 1974; Dell'Osso and Daroff, 1975). In congenital nystagmus no oscillopsia (apparent movement of the environment) is noticed.

Accepting that the congenital nystagmat has a

Correspondence to Dr R. V. Abadi. major visual problem, how can the clinician remedy the situation? In the past a number of techniques, both optical and surgical, have been attempted, though none seem able to provide a suitable method for the diversity of cases encountered. Moreover, the specific nature of these therapies do not make them readily modifiable (see Discussion).

It is the aim, therefore, of this paper to report a new method which should provide an improvement in visual sensitivity for most individuals with $\mathrm{CN}$. Simply, we proposed to let the subjects of our study hear their own eye movements and thereby attempt to use this feedback signal to control their nystagmus.

\section{Methods}

To be able to understand any eye movement disorder and monitor its improvement after therapy both the motor and sensory responses need to be examined. These include nystagmus intensity and the visual sensitivity.

\section{RECORDING THE EYE MOVEMENTS}

A modified photoelectric method was employed to monitor the nystagmus (Stark et al., 1962). Infrared sources (TIL 24) and receivers (LS 614) were used to detect changes in limbal reflection due to the involuntary horizontal nystagmus (Fig. 1). These devices were mounted on a small printed circuit board and attached to the spectacles of the observer (Fig. 2). The reflected infrared light is detected by the receiver and fed into a preamplifier, the resultant amplified signal being then used to control the frequency of a voltage-controlled oscillator operating in the audiorange of $200-2000 \mathrm{~Hz}$. The output of this oscillator, after amplification, is used to operate 
Fig. 1 The infrared source
and photocell receiver
arrangement for recording eye
movements

Fig. 1 The infrared source
and photocell receiver
arrangement for recording eye
movements

Fig. 1 The infrared source
and photocell receiver
arrangement for recording eye
movements

Fig. 1 The infrared source
and photocell receiver
arrangement for recording eye
movements

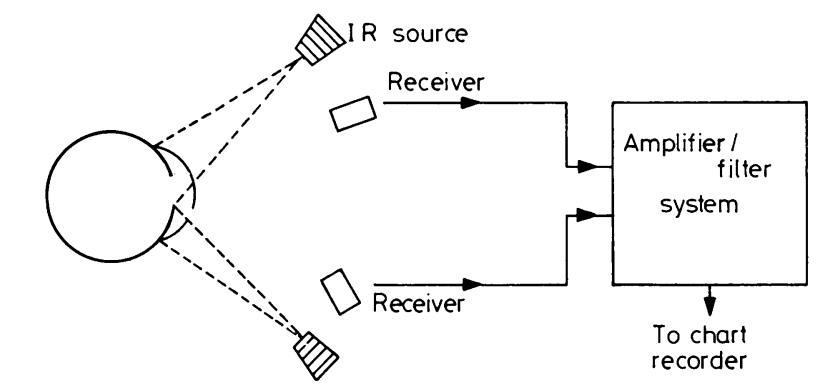

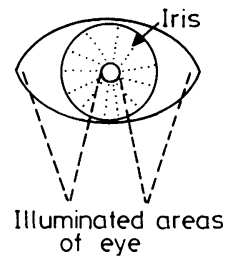

a small loudspeaker. Thus the subject can hear a tone, the frequency of which is altered by the eye movements.

Using this feedback device we have attempted to control the degree of nystagmus by asking the subjects to try to keep the tone constant. In order to assess the degree of success of this technique we monitored the intensity and velocity of the nystagmus, before, during, and after the course of training.

\section{MEASURING CONTRAST THRESHOLDS}

At all stages of training, psychophysical contrast sensitivity functions were measured to give an indication of improved visual sensitivity. Both vertical and horizontal sinusoidal grating patterns were generated on the face of a Telequipment D61 oscilloscope (P31 phosphor), and each observer was asked to find his own contrast threshold at different spatial frequencies by adjusting a potentiometer which altered the contrast of the patterns (Schade, 1956; Campbell and Green, 1965; Abadi, 1974b; Arden, 1978). The contrast of the grating pattern is defined as the ratio of the difference of the maximum and minimum luminance over their sum. Contrast sensitivity is the inverse of contrast threshold, and spatial frequency is an equivalent measure of bar size in a grating pattern; that is, it is the number of alternating pairs of dark and

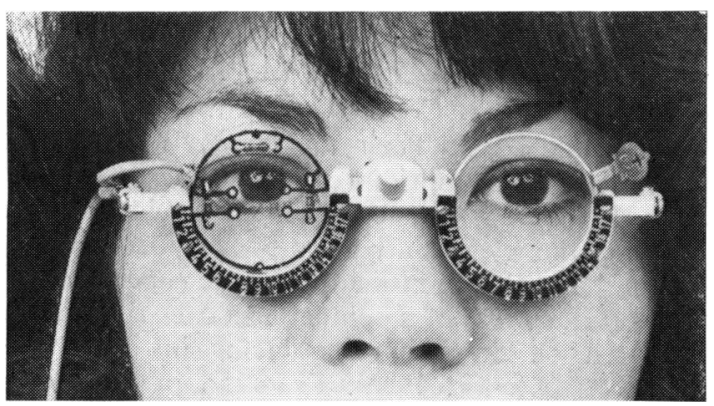

Fig. 2 Subject using the eye movement recording spectacles and listening for a change in tone from the speaker bright bands of the pattern subtended in degrees of visual angle at the observer's eye. The mean screen liminance was constant at $7 \mathrm{~cd} / \mathrm{m}^{2}$, subtending an angle of $8^{\circ}$ when the viewing distance was $57 \mathrm{~cm}$. Monocular viewing of the circular display was used throughout, and all subjects were fully corrected for any refractive errors.

\section{SUBJECTS}

Although we have now 'trained' a number of subjects to use the equipment, this paper will detail the typically favourable results achieved by describing the data of one such observer, a 22-year-old male. After trial runs in the laboratory he took the feedback equipment home and over a period of 24 weeks practised keeping the tone constant for 5-10 minutes each morning and evening.

\section{Results}

Contrast sensitivity functions for prefeedback and postfeedback are illustrated in Figs. 3a and $b$. The visual sensitivity to horizontal patterns is seen to be greater than that for vertical ones and confirms the earlier studies of Abadi (1974a) and Abadi and Sandikcioglu (1975). This effect is caused by the horizontal motion of the nystagmus and is not due to any uncorrected refractive error or meridional amblyopia from an uncorrected astigmatism acquired early in life. Indeed it has recently been demonstrated by Abadi and King-Smith (in press) that if the eye movements are eliminated the orientational sensitivity bias is still present, suggesting that the oculomotor disturbance may be responsible for depriving the cortical orientational detectors of a normal visual input and thus giving rise to a meridional amblyopia.

After feedback training visual sensitivity for both meridians is shown to have improved. Moreover the intensity of the nystagmus has been reduced from an initial level of $3.59^{\circ} \pm 0.36^{\circ} / 4.75 \mathrm{~Hz}$ $\pm 0.33 \mathrm{~Hz}$ to $2.64^{\circ} \pm 0.29^{\circ} / 3.88 \mathrm{~Hz} \pm 0.28 \mathrm{~Hz}$ (Fig. 3, insets). In terms of the velocity of the image moving in the back of the retina this would consti- 


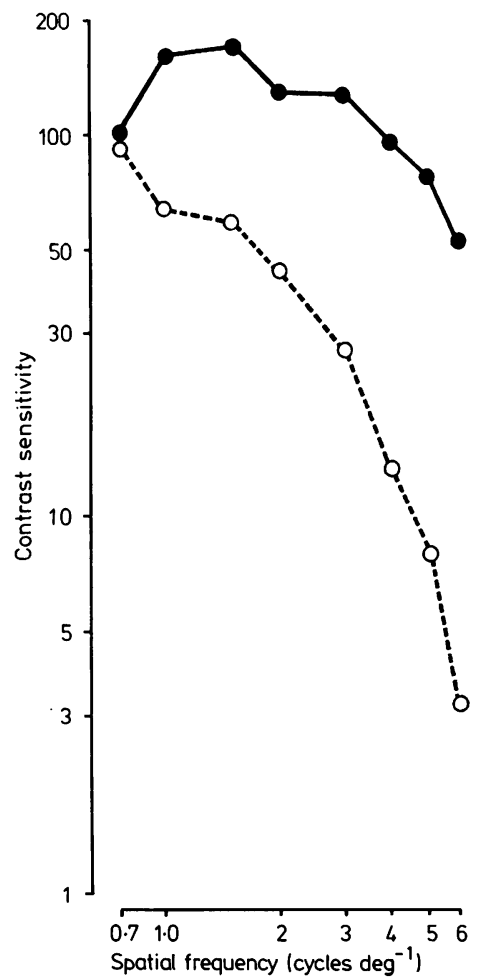

$3 a$
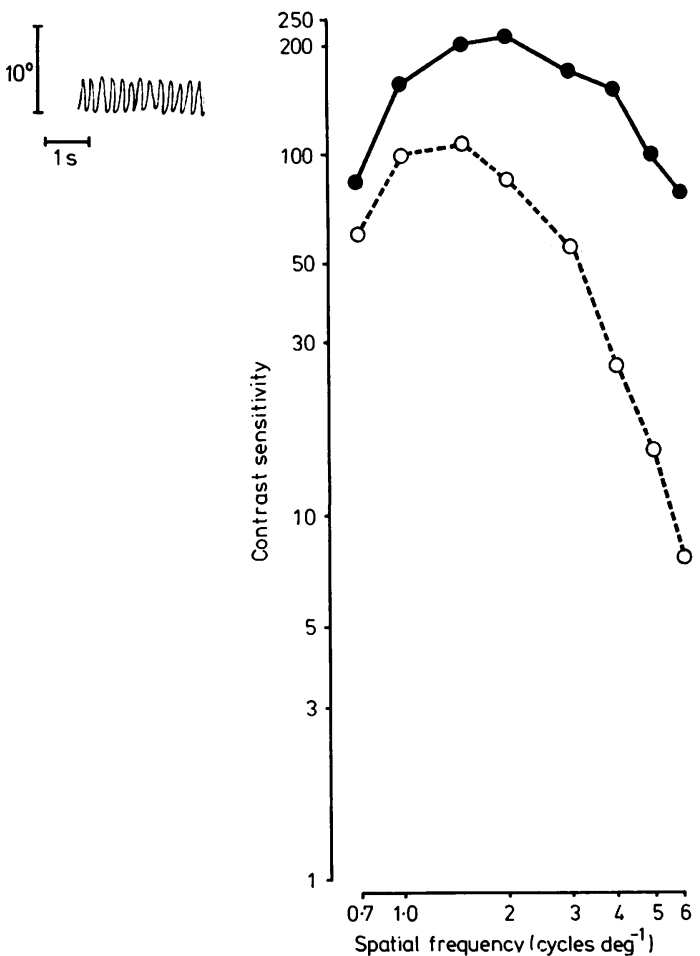

3b

Fig. 3 Spatial contrast sensitivity functions for an observer with congenital nystagmus before (a) and after (b) auditory feedback training. The filled and empty symbols refer to thresholds (mean of 20) in response to horizontally and vertically orientated patterns respectively. Insets illustrate the form and intensity of the nystagmus

tute an approximate reduction from a value of $54 \%$ to $32 \%$. Consequently the image, which is now less blurred, also spends more time on the fovea. Fig. 4 shows the postfeedback to prefeedback contrast sensitivity ratios for viewing a horizontal grating pattern (top) and a vertical pattern (bottom), indicating sensitivity improvements of $0.17(\times 1.5)$ and $0.30(\times 2.0) \mathrm{log}$ units respectively. This change was maintained after training had ceased.

In our studies the subjects were adults and showed feedback changes of between 0.13 to 0.32 $\log$ units.

\section{Discussion}

Using a biofeedback technique we are able to report that after training it is possible to improve the visual sensitivity and hence the visual resolution of adults with CN. Indeed this 'learned self-control' is also illustrated by a reduction in both the amplitude and frequency of the nystagmus (Fig. 3, insets). Of course, this does not mean that the familiar methods of management of nystagmus, namely, optical and surgical, will be replaced. Rather the training routine could augment these more traditional and specific therapies. Consequently it would not be out of order briefly to consider them here and reflect on their limitations.

TRADITIONAL MANAGEMENT OF NYSTAGMUS Optical treatment. Contact lenses have been used as an optical aid. Their advantages for patients with albinism or aniridia can be immense (Enoch and Hudson, 1968), because the incident light entering the eye can be more easily controlled. Claims have also been made that the superiority of the optical system of a contact lens over a spectacle lens can be an important factor in improving vision (Grosvenor, 1963). From an optical point of view the contact lens correction should provide fewer distortions and aberrations, and the prismatic displacements which occur with spectacle lenses 


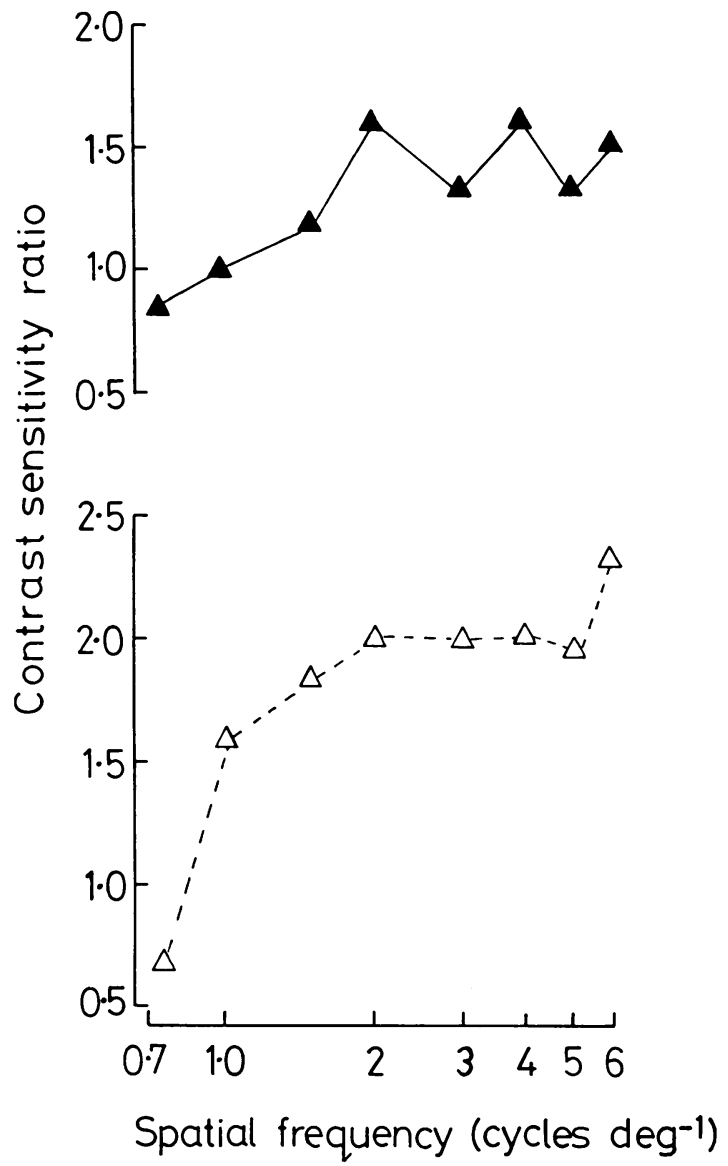

Fig. 4 Contrast sensitivity ratios comparing prefeedback with postfeedback data. The upper graph illustrates the postfeedback/prefeedback ratio for horizontal stimuli, and the lower graph shows the equivalent ratio for vertical stimuli

because of the moving eye are much reduced with the contact lens systems.

Quite often the amplitude and frequency of $\mathrm{CN}$ varies with positions of gaze, and in one direction, the neutral zone, the nystagmus intensity can be greatly reduced (Kestenbaum, 1953; Dell'Osso, 1973; Abadi and Sandikcioglu, 1974). The use of prisms to direct the eyes to this position has been attempted by Dell'Osso et al. (1972). With convergence providing the stimulus for an attenuation on the nystagmus intensity (Abadi and Sandikcioglu, 1974) baseout prisms have been used to induce this vergence (Metzger, 1950).

Surgical treatment. To place the neutral zone in the primary position of gaze a patient may take up a compensatory head posture. To prevent this torticollis surgical techniques are available to direct the eyes to coincide with this position. Two types of operations may be carried out. The first entails the relocation of the eyes by operating on all 4 horizontal recti (Anderson, 1953; Kestenbaum, 1953). The second, a more drastic approach, entails immobilisation, either by fixing the ocular muscles to the periostium (Friede, 1956) or by the less extreme retroequatorial recession method (Bietti, 1956; Crone, 1971).

\section{AUDITORY FEEDBACK}

The techniques just described are specialised solutions to particular aspects of $\mathrm{CN}$ and do not offer a general solution that is both practical and simple. For example, prism therapy relies on the existence of a marked neutral point. Alternatively, by using base in prisms it can present after short periods of time symptoms typical of eye strain (Wybar, 1974). Surgery is primarily attempted to counter torticollis and is complicated if a strabismus is also present. Moreover it is appropriate only if the nystagmus is jerky (both fast and slow phases). On the other hand, biofeedback offers the subject a self-trainer to be used either by itself or in conjunction with other optical or surgical methods.

Although the reported improvements in visual sensitivity never reached levels greater than $0.32 \mathrm{log}$ units, it may be argued that the visual system is far from plastic in adults (Barlow, 1975). A study is therefore now in progress to find the effects of the same training schedule on young children where the visual system is known to be more adaptable.

As a further use, this auditory signal technique can be extended to detecting and correcting other oculomotor deviations, for example, squints, and be used to train accurate fixation in individuals with amblyopia.

We thank Miss Wiggie for her comments and drawings and Miss Price for typing the manuscript. R. V. Abadi received financial support from the British Optical Association and the Visual Research Trust.

\section{References}

Abadi, R. V. (1974a). The effects of early anomalous visual inputs on orientation selectivity. Perception, 3, 141-150.

Abadi, R. V. (1974b). Visual analysis with gratings. British Journal of Physiological Optics, 29, 49-56.

Abadi, R. V., and King-Smith, P. E. Congenital nystagmus modifies orientation detection. Vision Research (in press).

Abadi, R. V., and Sandikcioglu, M. (1974). Electro-oculographic responses in a case of bilateral idiopathic nystagmus. British Journal of Physiological Optics, 29, 73-85.

Abadi, R. V., and Sandikcioglu, M. (1975). Visual resolution in congenital pendular nystagmus. American Journal of Optometry and Physiological Optics, 52, 573-581.

Anderson, J. R. (1953). Causes and treatment of congenital eccentric nystagmus. British Journal of Ophthalmology, 37, 267-281. 
Arden, G. B. (1978). The importance of measuring contrast sensitivity in cases of visual disturbance. British Journal of Ophthalmology, 62, 198-209.

Barlow, H. B. (1975). Visual experience and cortical development. Nature, 258, 199-204.

Bietti, G. B. (1956). Note di tecnica chirurgica oftalmologica. Bollettino d'Oculistica, 35, 642-656.

Campbell, F. W., and Green, D. G. (1965). Optical and retinal factors affecting visual resolution. Journal of Physiology, 181, 576-593.

Crone, R. A. (1971). The operative treatment of nystagmus. Ophthalmologica, 163, 15-20.

Dell'Osso, L. F. (1973). Fixation characteristics in hereditary congenital nystagmus. American Journal of Optometry and Physiological Optics, 50, 85-90.

Dell'Osso, L. F., and Daroff, R. B. (1975). Congenital nystagmus waveforms and foveation strategy. Documenta Ophthalmologica, 39, 155-182.

Dell'Osso, L. F., Gauthier, G., Liberman, G., and Stark, L. (1972). Eye movement recordings as a diagnostic tool in a case of congenital nystagmus. American Journal of Optometry and Physiological Optics, 49, 3-13.

Enoch, J. M., and Hudson, C. E. (1968). Remission of nystagmus following fitting contact lenses to an infant with aniridia. American Journal of Ophthalmology, 66, 333-335.

Fine, S. R. (1968). Blind and Partially Sighted Children. Education survey 4. Department of Education and Science. HMSO: London.

Forsythe, W. I. (1955). Congenital hereditary vertical nystagmus. Journal of Neurology, Neurosurgery, and Psychiatry, 18, 196-198.

Friede, R. (1956). Zur operativen Behandlung des Nystagmus gravis nebst Bermerkungen zur Extraktion der kongenitalen Kataract. Klinische Monatsblätter für Augenheilkunde, 128, 451-455.

Grosvenor, T. P. (1963). Contact Lens Theory and Practice pp. 340-341. Illinois Professional Press.

Hemmes, G. D. (1926). UUber hereditären Nystagmus. Zentralblatt für die gesamte Ophthalmologie und ihre Grenzgebiete, 13, 262.

Kestenbaum, A. (1953). Nouvelle operation du nystagmus. Bulletin de la Société d'Ophtalmologie de Paris, 6, 599602.

Marmor, M. F. (1973). Hereditary vertical nystagmus. Archives of Ophthalmology, 90, 107-111.

Metzger, E. L. (1950). Correction of congenital nystagmus. American Journal of Ophthalmology, 33, 1796-1797.

Norn, M. S. (1964). Congenital idiopathic nystagmus. Incidence and occupational prognosis. Acta Ophthalmologica, 42, 889-895.

Schade, O. H. (1956). Optical and photoelectric analog of the eye. Journal of the Optical Society of America, 46, 721-739.

Stark, L., Vossius, G., and Young, L. R. (1962). Predictive control of eye tracking movements. IRE Transactions of Human Factors in Electronics, Vol. HF3, pp. 52-56.

Wybar, K. (1974). The management of nystagmus. In Aspects of Neuro-ophthalmology. pp. 31-44. Edited by S. I. Davidson. Butterworths: London. 